\title{
STEM Students outside the Classroom: The Role of the Institution in Defin- ing Extracurricular Activity
}

\section{Dr. Denise Wilson, University of Washington}

Denise Wilson received the B.S. degree in mechanical engineering from Stanford University in 1988 and the M.S. and Ph.D. degrees in electrical engineering from the Georgia Institute of Technology in 1989 and 1995, respectively. She also holds an M.Ed. from the University of Washington (2008) and has worked in industry (Applied Materials). She is currently a faculty member with the Electrical Engineering Department, University of Washington, Seattle, and she was previously with the University of Kentucky, Lexington, in a similar position from 1996 to 1999. Her research interests are split between technical investment in biological and chemical-sensing microsystems and equivalent interest in engineering education, with particular emphasis on affective and metacognitive factors that influence student success in STEM fields.

\section{Dr. Cheryl Allendoerfer, University of Washington}

Dr. Allendoerfer is a Research Scientist in the College of Engineering at the University of Washington.

\section{Ms. Mee Joo Kim, University of Washington- Seattle}

Mee Joo Kim is a Ph.D. student in College of Education at University of Washington. She received her M.Ed. in Social Foundations (2009) from the Curry School of Education at University of Virginia. Her research interests include academic and civic engagement of college students majoring in STEM disciplines.

\author{
Elizabeth Burpee \\ Dr. Rebecca A Bates, Minnesota State University, Mankato \\ Dr. Tamara Floyd Smith P.E., Tuskegee University \\ Dr. Melani Plett, Seattle Pacific University \\ Dr. Nanette M Veilleux, Simmons College
}

Nanette Veilleux is an Associate Professor in the Computer Science and Information Technology Program at Simmons College. Her research fields are STEM pedagogy and Computational Linguistics. 


\title{
STEM Students outside the Classroom: The Role of the Institution in Defining Extracurricular Activity
}

\begin{abstract}
This paper examines participation in extracurricular activities among engineering, computer science, and mathematics students at five diverse institutions in the United States. Data were extracted from over 1200 survey responses to capture the time students spent in extracurricular activities and the nature of those activities. Our results show that within an institution, the extent of involvement in extracurricular activities is consistent among different types of students. No significant differences in total extracurricular involvement were found across gender or ethnicity within any single institution. The broadest variation occurred across institutions. While the two larger institutions demonstrated extracurricular involvement on par with national averages, the smaller institutions demonstrated wide variations from this average. Although this research is cross-sectional and not longitudinal in nature, we conclude from our results that institutional culture, rather than student characteristics, has the strongest influence on what students do and how often they do it within extracurricular communities.
\end{abstract}

\section{Introduction}

Participation in extracurricular activities often has a positive impact on the academic experience of students in middle and high school, as well as during the undergraduate years. While engineering majors may report lower satisfaction with the college experience than some other majors, the source of that dissatisfaction does not appear to be reflected in a lack of involvement in extracurricular activities. In fact, undergraduate engineering majors are on par with other majors in the amount of time spent on extracurricular activities. Extracurricular involvement can include a wide range of activities, which can have numerous academic and personal benefits (and some drawbacks). However, little is known about the nature of extracurricular involvement specifically among engineering and other STEM students, how it evolves year-to-year, and how it differs according to gender, ethnicity, and institutional culture. In this paper we analyze survey data to examine STEM undergraduate students' participation in extracurricular activities and communities at five diverse institutions, both in terms of how much time is spent and what they do during that time.

\section{Background}

Terminology: Some debate remains regarding the difference between extracurricular activities and co-curricular activities. In secondary school settings, extracurricular activities are often thought to be those that take place outside the school day, and co-curricular activities often refer to activities taking place during the school day. Since the school day is much less well defined in higher education, in this paper we refer to extracurricular and co-curricular activities interchangeably, not only due to the similarity in their meaning, but also due to the fact that in our survey instruments, the examples we attach to extracurricular activities are almost identical to the examples provided in the National Survey for Student Engagement (NSSE) when referring to co-curricular activities. 
In their 2005 study, Pascarella and Terrenzini ${ }^{1}$ wrote, "If there is a single adjective that describes the body of research on the impact of college conducted during the decade of the 1990s, it is "expansive"' (2005, Chapter 1). While that expansiveness has continued into the first decade of the twenty-first century, increased attention has been placed on student socioeconomic status, race, gender, and ethnicity, as well as how institutional characteristics relate to student success. ${ }^{1}$

While studies at the K-12 level have found that extracurricular activities have a predominantly positive impact on academic outcomes, findings have been mixed in studies of higher education. For example, higher education research has demonstrated positive links between intercollegiate athletics and academic persistence ${ }^{1}$, between extracurricular participation and critical thinking skills ${ }^{2}$, between sports or volunteering and grade point average ${ }^{3}$, and between extracurricular group involvement and increased satisfaction and academic success for black and Latino students ${ }^{4}$. Among the studies that have focused specifically on engineering undergraduates, Wilson et al. ${ }^{5}$ found a link between extracurricular social connections and women's persistence in engineering, and research coming from the NSF-funded Center for the Advancement of Engineering Education (CAEE) has identified the importance of participation in extracurricular communities for academic success ${ }^{6-10}$. A study at Purdue University, which has one of the largest engineering colleges in the United States, showed that students who engage in cocurricular activities have higher GPAs and more credit hours than the their peers, a performance advantage that only increases when controlling for SAT scores, academic major and other factors ${ }^{11}$. In another study ${ }^{12}$, students who report higher levels of social integration throughout their college experience also had higher GPAs upon graduation. Consistent with this study, Choudhary ${ }^{13}$ found that engineering students who were involved in co-curricular activities generally performed better than those who did not.

However, equally valid studies show negative connections between extracurricular activities and academics, including Brint and Cantwell's study ${ }^{3}$ showing weak and inconsistent links between activities and students' connections to campus life, and negative effects on grade point averages for those working off campus. Likewise, LaNasa, Olson, and Alleman ${ }^{14}$ also found no significant relationship between extracurricular activities and cumulative grade point average among first-year students at a doctoral research university in the Midwest. These results seem inconsistent with research involving the general population that shows that leisure activities in general are beneficial for people, providing opportunities for promoting life balance as an oasis for holistic personal renewal as well as facilitating resilience and coping ability with regard to stress $^{15-18}$.

Clearly, despite the fact that there has been continued expansion and diversification of research paths overall, consistent evidence regarding the impact of extracurricular activities on academic outcomes remains limited. One reason for this lack of evidence may be that extracurricular activities are far more varied and institution-dependent in college than in high school. Institutional variation in the availability of extracurricular activities, students' availability to participate in these activities, and campus cultures may indicate that some extracurricular activities have more benefit than others on student academic activity at any one school. In fact, some extracurricular activities may even be detrimental to academic outcomes. This research study investigates whether institutional culture plays a major role in the types of activities students choose, the amount of time they spend in those activities, and whether the association 
between these activities and academics varies significantly from institution to institution.

\section{Methods}

A quantitative approach was used to explore the amount of time that students in certain STEM majors (engineering, computer science, and mathematics) spend in extracurricular activities, and also the nature of that involvement. Students in engineering, computer science, and mathematics from five different higher education institutions across the United States participated in this study. These institutions, their Carnegie Classifications ${ }^{19}$, and their key characteristics as drawn from institutional data and mission statements are as follows:

- HBCU (Bac-Div): An historically black, independent, and state-related institution of 3000 students in the Southeast which offers seven undergraduate engineering degrees and is typically characterized by small groups of students (class sizes of 5-50). Students can begin the engineering curriculum as early as first semester freshman year.

- Private/Faith Based (Masters L): A small teaching institution in the Pacific Northwest of 4,000 students, whose mission emphasizes building graduates of competence and character by providing tools of rigorous learning and modeling a grace-filled community. This institution offers four engineering and computer science majors that are based on and informed by a Christian world view. Class sizes typically range from 15-20.

- Research (RU/VH): A large research institution and flagship university in the Pacific Northwest serves over 92,000 students and offers over 12,000 degrees annually. This institution offers ten engineering and computer science undergraduate degrees, and is characterized by large classes in freshman and sophomore years (100-500) and smaller classes in junior (40-80 students) and senior year (15-40 students). Classes are commonly supported by multiple teaching assistants and contact with faculty is less frequent than at the other four schools in this study.

- Teaching (Masters L): A medium-sized institution of over 10,000 students in the Midwest that combines an emphasis on teaching with emerging innovations in research, serving a regional student population. This institution offers over ten undergraduate degrees in engineering and computer science. Class sizes typically average 25 students, with upper division classes averaging about 15 students.

- Women's (Masters L): A small women's college of approximately 1,900 students in the Northeast with fifty majors, including three computer science and related degrees. This institution offers a liberal arts education for its undergraduates integrated with professional work experience. Class sizes are typically 6-12 students, with the largest class size around 20.

The five institutions were deliberately chosen in order to capture undergraduate experiences in a wide range of institution types that vary significantly by size (enrollments), variety of established engineering and computer science majors, institutional culture, and diversity of undergraduates on campus. 


\section{A. Research Questions}

Our research questions focus on variations in extracurricular involvement among undergraduate engineering, computer science, and math students as a function of institutional culture, gender, and ethnicity.

\section{Research Question \#1: How does extracurricular involvement vary across gender?}

Significant differences across gender, either in the nature of involvement in extracurricular activities or in the amount of involvement may indicate that men and women are experiencing different overall benefits to their academic endeavors from participation in extracurricular activities. Knowing what these differences are can help educators support extracurricular activities for men and women that are not only beneficial to academic, intellectual, and personal development, but are also most likely to increase extracurricular participation from each gender.

\section{Research Question \#2: How does extracurricular involvement vary across ethnicity?}

Similar to understanding differences across gender, capturing and understanding differences in extracurricular involvement across ethnicity (especially between majority and underrepresented minority groups) can enable educators to support activities that promote increased academic involvement, success, and fulfillment.

\section{Research Question \#3: How does extracurricular involvement vary across institutions?}

Significant differences across institutions in nature and type of extracurricular involvement will warn against making our findings generalizable. The nature, amount, and fabric of extracurricular involvement may be as unique as each institution, dependent on local culture, institutional history and tradition, institution size, and a variety other factors. If institutional differences are significant, approaches to encouraging, supporting, and guiding extracurricular involvement will need to be developed uniquely at institutions, using results from similar institutions as a starting point rather than relying on results from a larger, but heterogeneous group of institutions. Regardless of the nature of significant differences within gender, ethnicity, and institution, we anticipate that findings regarding the degree of variation among demographic groups as well as among institutional cultures will contribute to the existing body of knowledge by providing a more nuanced understanding of the activities that impact our students.

\section{B. Subjects and Procedures}

A total of over 1200 undergraduate engineering, computer science, and mathematics students were recruited from these five institutions, and began participation in this study by completing a survey of their experiences. Students reported on their participation in communities both in and outside of school, as well as their feelings about the degree to which they belong (or do not belong) in these communities. The distribution of survey participants by major is summarized in Table 1. 
Table 1: Demographics of Undergraduate Study Population

\begin{tabular}{|l|l|c|c|c|c|c|c|}
\hline \multicolumn{2}{|l|}{} & \multicolumn{6}{|c|}{$N(\%)$} \\
\hline Demographic & HBCU & Private & Teaching & Research & Women's & Total \\
\hline Total & All & $\begin{array}{c}156 \\
(12.9 \%)\end{array}$ & $\begin{array}{c}7 \\
(7.1 \%)\end{array}$ & $\begin{array}{c}276 \\
(22.7 \%)\end{array}$ & $\begin{array}{c}679 \\
(55.8 \%)\end{array}$ & $\begin{array}{c}18 \\
(1.5 \%)\end{array}$ & $\begin{array}{c}1217 \\
(100 \%)\end{array}$ \\
\hline Gender & Men & 99 & 58 & 173 & 490 & 0 & 820 \\
& & $(63.1 \%)$ & $(66.7 \%)$ & $(62.7 \%)$ & $(72.2 \%)$ & & $(67.4 \%)$ \\
\hline & Women & 58 & 29 & 98 & 185 & 18 & 388 \\
& $(36.9 \%)$ & $(33.3 \%)$ & $(35.5 \%)$ & $(27.2 \%)$ & $(100 \%)$ & $(67.4 \%)$ \\
\hline Ethnicity & Black & 140 & 2 & 10 & 12 & 2 & 166 \\
& & $(89.2 \%)$ & $(2.3 \%)$ & $(3.6 \%)$ & $(1.8 \%)$ & $(11.1 \%)$ & $(13.6 \%)$ \\
\hline & Asian* & 0 & 10 & 21 & 220 & 4 & 278 \\
& & & $(11.5 \%)$ & $(7.6 \%)$ & $(32.4 \%)$ & $(22.2 \%)$ & $(22.9 \%)$ \\
\hline & Caucasian & 0 & 58 & 217 & 349 & 9 & 633 \\
& & & $(66.7 \%)$ & $(78.6 \%)$ & $(51.4 \%)$ & $(50.0 \%)$ & $(52.0 \%)$ \\
\hline & Hispanic & 2 & 2 & 4 & 13 & 1 & 22 \\
& & $(1.3 \%)$ & $(2.3 \%)$ & $(1.4 \%)$ & $(1.9 \%)$ & $(5.6 \%)$ & $(1.8 \%)$ \\
\hline & Biracial & 11 & 8 & 7 & 28 & 2 & 56 \\
& $(7.0 \%)$ & $(9.2 \%)$ & $(2.5 \%)$ & $(4.1 \%)$ & $(11.1 \%)$ & $(4.6 \%)$ \\
\hline
\end{tabular}

* Includes South Asian/South Asian American and Asian/Asian American

The sample included 1217 students who reported being in an engineering, computer science, math, or pre-engineering major. The mean age of the sample was 21.5 years and their mean reported grade point average was 3.33. The sample included sophomores (271 or 27.7\%), juniors ( 463 or $45.7 \%$ ), and seniors ( 233 or $23 \%$ ) including fifth year seniors. The ethnic make-up of the sample was primarily White (52\%), Asian/Asian American (22.9\%) and African American/Black (13.6\%). Detailed demographics are summarized in Table 1, and related survey questions are presented in Table 2. This data analysis emphasizes demographic groups that constituted $1 \%$ or more of the total sample. Native American $(0.5 \%)$, Arab (0.8\%), African $(0.2 \%)$, Multiracial $(0.9 \%)$ and Other $(0.5 \%)$ ethnic populations were present below this $1 \%$ threshold. 
Table 2: Relevant Demographic Survey Questions

\begin{tabular}{|l|l|}
\hline Question & Response Scale \\
\hline Gender (circle one) & (1) Female \\
& (2) Male \\
\hline Your Ethnicity & (1) American Indian/Native American \\
(check as many as apply for you) & (2) African American/Black \\
& (3) Arab/Middle Easterner \\
& (4) Asian/Asian American \\
& (5) Caucasian/White \\
& (6) Hispanic/Latina/Latino/Mexican American \\
& (7) Pacific Islander \\
& (8) South Asian/South Asian American \\
& (9) Other, please specify \\
\hline
\end{tabular}

\section{Instruments}

Quantitative survey data were used to answer the three research questions in this study.

Additional information regarding this survey is described by Plett, Jones, Crawford et al. ${ }^{20}$. One survey question asked students to report how much time they spent in extracurricular activity every week, and a series of Likert scale questions then probed for more detail regarding the nature of this extracurricular involvement (see Table 3). The types of extracurricular activities identified in the Likert scale questions were extracted from a previous tool development phase of this research project, where students identified the activities in which they most participated. The extracurricular activities that were mentioned most frequently in this tool development phase were then integrated into the survey. Therefore, the extracurricular activities noted in Table 3 represent a majority of what our study participants do outside the classroom. A separate block of questions addressing discipline-specific activities was also included in this survey (design competitions, labs, undergraduate research, etc.); however, those results are not included in this analysis. 
Table 3: Questions Regarding Extracurricular Activities Used in This Study

\begin{tabular}{|l|l|}
\hline Question & Response Scale \\
\hline $\begin{array}{l}\text { On average, how many hours do you spend per } \\
\text { week in extracurricular activities (religious } \\
\text { organizations, book club, fraternity, professional } \\
\text { societies, etc.)? }\end{array}$ & Short Answer \\
\hline $\begin{array}{l}\text { Select one response for each item to describe your level } \\
\text { of participation in the following types of activities or } \\
\text { communities: }\end{array}$ & \\
International Student Groups & \\
Music (Dance, Band, Choir, etc.) & \\
$\begin{array}{l}\text { On-Line Social Networks and other On-Line } \\
\text { Communities }\end{array}$ & (1) No Participation \\
Religious Activities & (2) Minimally Active \\
Sorority or Fraternity & (3) Somewhat Active \\
Sports & (4) Active \\
Shared Living Groups & (5) Very Active \\
Student Government & \\
Summer Outreach Camps & \\
University Community & \\
Work Communities (including volunteer work) & \\
\hline
\end{tabular}

\section{Data Analysis}

Descriptive statistics, including mean and standard deviation (SD), were tabulated for each of the extracurricular activity questions in Table 3. Comparisons of the sample means were evaluated through one way analysis of variance (ANOVA), the results of which were identical to a t-test when only two groups were involved in the comparison. Statistical significance was evaluated at 0.05 and 0.01 . The significance of these levels included a correction (Tukey's honest significant test, i.e., Tukey's HSD) to account for Type 1 error in multiple group comparisons. Tukey's HSD compares all possible pairs of means and is based on a distribution similar to the t-test that produces a conservative confidence level when unequal sample sizes are involved in the ANOVA $^{21}$.

\section{Results and Discussion}

Our results show surprisingly few differences across gender and ethnicity, but multiple differences among the five institutions in this study. As a result, gender and ethnicity are evaluated both in total and within each institution (to avoid confounding effects from variations in institutional culture).

\section{A. Research Question \#1: How does extracurricular involvement vary across gender?}


We first examined whether extracurricular participation differs significantly between men and women. Descriptive statistics for extracurricular involvement at all five institutions are broken down by gender and summarized in Table 4. No significant differences were found by gender at any of the five institutions, although it appears that men may be spending more time in extracurricular activities than women. In fact, at the research institution, this difference was emerging as significant $(\mathrm{p}=0.088)$.

Table 4: Amount of Time spent in Extracurricular Activities by Gender*

\begin{tabular}{|l|c|c|c|c|c|c|}
\hline & \multicolumn{5}{|c|}{ Hours Spent on Extracurricular Activities per Week: Mean (SD) } \\
\hline Gender & Total & HBCU & Private & Teaching & Research & Women's \\
\hline Men & $8.1(9.8)$ & $12.1(10.5)$ & $9.7(7.9)$ & $7.0(10.2)$ & $7.4(9.5)$ & N/A \\
\hline Women & $7.4(7.7)$ & $10.7(10.4)$ & $8.4(6.2)$ & $7.2(8.6)$ & $6.2(6.1)$ & $7.1(6.5)$ \\
\hline
\end{tabular}

*Includes all ethnic categories

\section{B. Research Question \#2: How does extracurricular involvement vary across ethnicity?}

We next examined the data to determine whether extracurricular participation differs significantly across ethnic group lines. Descriptive statistics for extracurricular involvement at all five institutions, broken down by major ethnic groups, are shown in Table 5.

Table 5: Amount of Time spent in Extracurricular Activities by Ethnicity*

\begin{tabular}{|l|c|c|c|c|c|c|}
\hline & \multicolumn{5}{|c|}{ Hours Spent on Extracurricular Activities per Week: Mean (SD) } \\
\hline Ethnicity & Total** & HBCU & Private & Teaching & Research & Women's \\
\hline Asian & $6.7(7.1)$ & NA & $6.5(4.7)$ & $7.7(7.5)$ & $6.5(7.1)$ & $8.4(11.2)$ \\
\hline Black & $10.3(9.8)$ & $11.3(10.1)$ & $8.0(0.0)$ & $4.6(2.3)$ & $4.0(5.8)$ & $0.8(1.1)$ \\
\hline Caucasian & $7.5(9.5)$ & NA & $9.1(7.0)$ & $7.2(10.2)$ & $7.4(9.6)$ & $7.1(4.5)$ \\
\hline Hispanic & $5.3(4.8)$ & $1.0(1.4)$ & $5.0($ N/A) & $2.0(1.6)$ & $6.7(4.9)$ & $13.0($ N/A) \\
\hline
\end{tabular}

*Includes only the 4 ethnic categories listed; participants identifying only with other ethnic categories are not represented in these figures.

**Significant differences were found in this category within $p<0.01$

No significant differences were found by ethnicity within any institution when considered individually. When considered together (in the Total column in Table 5), Black students spent considerably more time in extracurricular activities than both Asian and Caucasian students. However, since the majority of Black students in the overall population were at the HBCU, it is likely that institutional differences between the HBCU and other schools were responsible for this difference, rather than an inherent difference in the way students of different ethnicities choose to participate in extracurricular activities within a particular institution. 
The findings for Research Questions 1 and 2 indicate that neither gender nor ethnic differences are strongly associated with how much time engineering students will spend on extracurricular activities. Rather, there appear to be more pronounced differences among institutions than among these two major demographics. Therefore, our next research question examines students' extracurricular participation at the institutional level.

\section{Research Question \#3: How does extracurricular involvement vary across institutions?}

To identify institutional differences in extracurricular participation, we first looked at the amount of time spent in these activities by students at each institution. The total amount of hours spent in extracurricular activities every week is reported for all five institutions in Table 6. Within the institutions in this study (Table 6), the HBCU students (11.6 hours per week) demonstrated a significantly higher amount of involvement than the Teaching (7.1 hours) and Research (7.1 hours) institutions $(\mathrm{p}<0.001)$.

Table 6: Amount of Time Spent in Extracurricular Activities at Participating Institutions

Data include engineering, computer science, and math sophomores, juniors, and seniors

\begin{tabular}{|l|l|c|c|c|}
\hline \multirow{2}{*}{} & & & \multicolumn{2}{|c|}{$\begin{array}{c}\text { Hours Spent on Extracurricular Activities per } \\
\text { Week }\end{array}$} \\
\hline Institution Type & Population & $\mathrm{N}$ & Mean & SD \\
\hline Bac-Diverse & HBCU & 150 & 11.6 & 10.5 \\
\hline Masters-L & Private & 84 & 9.3 & 7.3 \\
\hline & Teaching & 246 & 7.1 & 9.6 \\
\hline & Women's & 16 & 7.1 & 6.5 \\
\hline Doc RU-VH & Research & 636 & 7.1 & 8.7 \\
\hline
\end{tabular}

These data can be compared to some extent to national averages as reported by the NSSE $(2012)^{22}$ (see Table 7); however, it is important to note that a direct comparison cannot be made because the study populations differ. The student populations in this study include sophomores, juniors, and seniors, while the NSSE study included only seniors. However, two of the smaller schools (HBCU, Private) consistently show many more hours spent in extracurricular activities (Table 6) than the national averages for their types of institutions (Table 7). Time spent in extracurricular activities was similar for the Teaching, Research, and Women's institutions compared to NSSE data, but students at the HBCU and Private institutions reported far more hours in extracurricular activities every week than the national averages in their category of institution. This result suggests that these institutions may be unique in some way that promotes a stronger investment in extracurricular activity. 
Table 7: Amount of Time Spent in Extracurricular Activities Nationally (NSSE, 2012)

Data include seniors of all majors

Mean \& SD estimated using same technique as NSSE 2011 Annual Report $^{20}$

\begin{tabular}{|l|c|c|c|}
\hline Institution Type & $\mathbf{N}$ & Mean & SD \\
\hline Bac-Diverse & 668 & 5.65 & 7.34 \\
\hline Masters-L & 3,616 & 4.72 & 6.57 \\
\hline Doc RU-VH & 7,484 & 5.93 & 7.00 \\
\hline
\end{tabular}

In order to unpack the results in Table 6, we look at extracurricular culture at each institution for each of the five institutions in this study. A discussion of institutional context and culture among the five institutions in this study as is relevant to extracurricular involvement follows.

Research University: Although the significance of the difference cannot be tested, engineering, computer science, and math students at this university appear to spend more time in extracurricular activities than students of all majors in Doc RU-VH institutions nationally. This result is consistent with the fact that nationally, engineering students spend more time (at least six hours per week) in these activities than most other majors ${ }^{23}$. As with many research institutions, at this university engineering is considered to be one of the most difficult majors on campus, and some engineering students immerse themselves in their studies to the exclusion of most everything else, including extracurricular activities. Computer science is combined with computer engineering in the same department and has a similar culture; math majors have a similarly challenging curricular experience. Classes are competitive, labs are time-intensive, and design projects are demanding, giving engineering classes a reputation for more hours spent per credit hour than other majors.

Teaching University: Similar to the Research institution, engineering, computer science, and math students appear to spend only slightly more time in extracurricular activities than students of all majors in Master's L institutions nationally (NSSE, Table 7). Many students in this institutional culture go home on weekends despite having campus or near-campus based residences (a quasi-commuting campus), which limits time for their studies and more importantly, time for extracurricular activities. As with the Research university, the academic culture at the Teaching university is competitive, and engineering, computer science, and math are reputed to be some of the more rigorous majors. Many students choose full immersion in their studies and families to the exclusion of other activities.

Private University: Unlike the Teaching and Research institutions, engineering, computer science, and math students at the Private university appear to spend far more time in extracurricular activities than students of similar majors at other Masters L institutions around the country. Students at the Private university are constantly bombarded with recruitment to a wide array of extracurricular activities, ranging from service projects to sports to engineering clubs. Many engineering classes encourage (sometimes with extra credit) or even require some participation in engineering club activities. Also, the private university is faith-based, so many students regularly spend one or two hours per week attending church. The school culture 
promotes extracurricular involvement as a valuable and integral part of undergraduate education; thus, the higher number of hours (9.3 per week) compared to the two institutions examined above would be expected. Although this level of involvement does not emerge as statistically significant, this is likely a result of small sample size, which is an unavoidable consequence of the small overall enrollment at the Private university.

HBCU: Similar to the Private university, students at the HBCU are likely to spend, on average, more time on religious activities every week than students at other institutions. While at the Private university this difference can be attributed to the emphasis on faith and religious practice in the university's mission, at the HBCU, this difference is likely due more to a regional emphasis on religious practice. More residents of the state in which the HBCU is located attend religious services every week (51-60\%) than in the states where the Research, Private, and Teaching universities are located (31-40\%), as well as the state where the Women's college is located (6-10\% ${ }^{24}$. Likewise, African-Americans/Blacks tend to devote more time to religious activities than Caucasians and Asians ${ }^{25}$. These trends, combined with the fact that students at the HBCU perceive employability to be enhanced by extracurricular involvement, contribute to explaining why HBCU students have significantly more extracurricular involvement than the Teaching and Research institutions.

Women's College: Two factors are likely to explain the Women's college students' lower participation in the types of extracurricular activities found to be popular at the other two small institutions in this study. First, as just discussed, residents of this college's geographical region (the Northeast) spend significantly less time in religious activities every week than residents living in geographical areas represented by the other four institutions. Second, the Women's college has the highest tuition among the five institutions in this study, and a majority of students (61.6\% of first year students and $85.6 \%$ of seniors) work during the academic year ${ }^{26}$, thus diminishing available time to participate in other types of extracurricular activities.

In summary, overall extracurricular involvement (measured in hours per week) seems to vary with identifiable but different factors across the five institutions studied. Variations in religious involvement by culture (geographical or school-based) as well as a need to work (Women's college) or attend to family (Teaching university) may play a strong role in determining extracurricular involvement. Thus, it may be that availability to participate in extracurricular activities (including encouragement to do so within the institutional culture) plays a stronger role in determining ultimate involvement in these activities than a desire to participate among our students.

In addition to examining the amount of time spent in extracurricular activities, we also looked at how the types of extracurricular activities or communities in which students spend this time differed across institutions. Students' levels of participation in each of the most popular extracurricular activities, as determined by a previous tool development phase of this research, were captured using the second question in Table 3. Results are summarized in in Table 8. 
Table 8: Level of Activity in Extracurricular Activities by Institution A score of 1 indicates "No Participation," and 5 indicates "Very Active"

\begin{tabular}{|l|l|l|l|l|l|}
\hline \multirow{2}{*}{ Extracurricular Activity } & \multicolumn{5}{l}{ Degree of Activity: Mean (SD) } \\
\cline { 2 - 7 } & HBCU & Private & Teaching & Research & Women's \\
\hline International Groups & $1.3(0.8)$ & $1.6(1.1)$ & $1.5(1.0)$ & $1.4(0.9)$ & $1.6(0.9)$ \\
\hline Music & $2.1(1.5)$ & $2.4(1.5)$ & $1.6(1.1)$ & $1.6(1.0)$ & $2.3(1.6)$ \\
\hline On-Line Communities & $3.7(1.4)$ & $1.4(0.2)$ & $2.9(1.2)$ & $2.7(1.2)$ & $3.6(1.0)$ \\
\hline Religious Activities & $3.2(1.2)$ & $3.0(1.4)$ & $1.8(1.1)$ & $2.0(1.3)$ & $2.3(1.6)$ \\
\hline Shared Living Groups & $3.4(1.5)$ & $3.5(1.4)$ & $2.9(1.5)$ & $2.7(1.5)$ & $3.2(1.4)$ \\
\hline Sorority or Fraternity & $1.4(1.1)$ & $1.2(0.7)$ & $1.1(0.6)$ & $1.7(1.2)$ & $1.3(0.8)$ \\
\hline Sports Teams & $2.4(1.6)$ & $3.2(1.5)$ & $2.5(1.4)$ & $2.5(1.4)$ & $2.3(1.7)$ \\
\hline Student Government & $1.7(1.1)$ & $1.2(0.5)$ & $1.2(0.6)$ & $1.3(0.7)$ & $1.9(1.3)$ \\
\hline Summer Camps & $2.0(1.3)$ & $1.6(1.1)$ & $1.3(0.7)$ & $1.3(0.8)$ & $1.6(1.0)$ \\
\hline University Community & $3.4(1.1)$ & $2.6(0.8)$ & $2.5(1.0)$ & $2.4(1.0)$ & $3.4(0.7)$ \\
\hline Work Communities & $3.1(1.3)^{1}$ & $2.3(1.2)$ & $2.4(1.3)$ & $2.4(1.2)$ & $3.5(1.1)$ \\
\hline
\end{tabular}

Next we examine trends in activity within each of the five institutions in the context of Table 8 .

Research University: Trends in student involvement at the Research university are similar to trends seen at the Teaching university. Engineering and computer science students at the Research university are most involved in shared living groups and on-line communities, and least involved in student government and summer camps. Housing costs both on and near campus are high and most students share living space with multiple other students, which likely contributes to active participation in shared living groups. High participation in on-line communities is consistent with national trends where $92 \%$ of young people aged 18-29 use social networking sites $^{27}$. Low participation in summer camps may be expected, since only one out of the university's five elementary and middle school summer camps is STEM-related, and fewer than $25 \%$ of the short courses for middle and high school students are STEM-related (furthermore, most STEM offerings focus on computer science rather than engineering). Compounding the lack of offerings in STEM summer camps is the fact that most engineering students, after they begin the core of their programs in their sophomore year, complete internships over the summer in preparation for their careers. Student government also has low participation among engineering, computer science, and math students which, while common among several of the five institutions in this study, does not have an immediate explanation. 
Teaching University: At the teaching university, students are most active in shared living groups and on-line communities and least active in sororities/fraternities, summer camps, and student government. The high degree of participation in shared living groups reflects the overall culture at the institution. For example, many students within this university's engineering programs start out in the university's engineering or "women in science and engineering" learning communities. In their remaining years, students often stay in similar dormitory floors or find off-campus housing with other engineering and science students. Sharing living spaces with students with similar work expectations seems to work best for these students. At the other end of the spectrum, low levels of participation in certain types of activities may be expected for the following reasons: Greek life at this university has low visibility and there are no STEM-specific fraternities or sororities; student government is primarily populated with students from majors other than STEM; and the university offers just one STEM-related summer camp, in which only a few STEM undergraduates typically participate. While many students work, they may not see themselves involved with their work community in other ways.

Women's College: At the Women's college, students are most active in on-line communities, university communities, and work communities, and least involved in sororities. The high degree of participation in student government and university community activities likely reflects the college's emphasis on -- and student government funding of -- club participation. In fact, each club is required to have a student government representative at weekly meetings. The equally high degree of participation in work communities may reflect the college's character as a small, private, tuition-dependent institution and the correspondingly high need to work at paying jobs among students attending this institution. On-line community participation is consistent with most other institutions in this study and national trends. This college does not have official sororities, which explains the students' lack of participation in this type of community.

Private University: At the Private university, students are most active in religious activities, shared living groups and sports. This is consistent with the institutional culture which is faithbased, and a majority of students value connection to church and related activities. High participation in shared living groups corresponds to the fact that this is a largely residential campus, with active living group communities. Finally, the university has many very competitive sports teams and an active intramural sports program which attract students, including STEM majors. In contrast, students are least involved in sororities/fraternities (since this institution does not have any), summer camps, and on-line communities. The low participation in on-line communities is somewhat surprising; however, this is an active, small, relational campus, so it is likely that students' time is filled with face-to-face communities, reducing the amount of time available for on-line communities.

$H B C U$ : Students at the HBCU report particularly high degrees of participation in on-line communities, shared living groups, university community, and religious activities. On-line community participation is consistent with most other institutions in this study and national trends. As a small, private school, one would expect significant involvement in the university community and shared living groups. Regarding students' involvement in religious groups, a high level of activity is expected based on geographical location and ethnicity of students (as discussed previously). Finally, approximately two-thirds of the students at the HBCU require 
financial aid, suggesting that these students might also supplement financial aid with paid employment, and therefore spend significant hours per week in work communities ${ }^{28}$.

While these facets of institutional culture explain many trends within institutions with regard to level of activity in different extracurricular activities, significant differences across institutions are captured in Table 9.

Table 9: Institutional Differences in Level of Extracurricular Activity (Only significant differences are shown; refer to Table 8 for descriptive statistics)

\begin{tabular}{|l|l|l|}
\hline Type of Activity & Highest Level of Activity & Lowest Level of Activity \\
\hline Music** & HBCU, Private & Teaching, Research \\
\hline On-Line Communities** & HBCU & Private, Teaching, Research \\
\hline Religious Activities** & HBCU, Private & Teaching, Research \\
\hline Shared Living Groups** & HBCU, Private & Teaching, Research \\
\hline Sorority or Fraternity* & Research & HBCU, Private, Teaching \\
\hline Sports Teams** & Private & HBCU, Teaching, Research \\
\hline Student Government** & HBCU, Women's & Private, Teaching, Research \\
\hline Summer Camps** & HBCU & Private, Teaching, Research \\
\hline University Community* & HBCU & Private, Teaching, Research \\
\hline
\end{tabular}

** Differences between Highest and Lowest level of activity were significant within $\mathrm{p}<0.01$

* Differences between Highest and Lowest level of activity were significant within $p<0.05$

Overall, the general trend seems to be that the smaller institutions tend to show higher levels of activity in popular extracurricular activities. This is consistent with the finding that these students spend more time in extracurricular activities overall. For example, HBCU and Private university students showed significantly higher levels of participation in music, religious activities, and shared living groups than students at the other institutions. HBCU students also had significantly higher levels of participation in on-line communities, summer camps, and university community. Students at the Women's college and the HBCU reported higher levels of participation in student government than students at the other schools, while Private university students showed higher participation in sports. The Research university students showed significantly higher levels of participation only in sororities and fraternities. These findings are consistent with the institutional characteristics discussed above.

Clearly, the institutional differences in extracurricular activity are more varied than those that occur across gender and ethnicity. However, it would be a mistake to assume that more is better, as not all extracurricular activities are created equal. Some have clear positive benefits to the student's academic experience, some have mixed impacts, and some even have negative 
impacts. For example, participation in music and religious organizations has been found to positively impact academic achievement ${ }^{29-30}$. Similarly, participation in communities such as religious organizations and clubs has been shown to meet students' needs for belonging, safety, and self-esteem, which in turn can facilitate academic engagement ${ }^{31}$. On the other hand, high levels of participation in on-line communities have been shown to have a negative effect on academic performance ${ }^{32}$. In this study, it appears that students at smaller institutions are achieving noteworthy benefits in academic achievement compared to the larger schools in this study, based on higher levels of involvement in music organizations, religious activities, and shared living groups.

This variation along institutional lines in students' amount and nature of extracurricular participation is important to note because of the potential link between such participation and academic performance. If, as many studies suggest, a certain degree of extracurricular participation - particularly in certain types of activities -- is beneficial for students' academic performance, students such as those at the larger institutions in this study may not be realizing the same benefits as those at the smaller institutions. At institutions where we see patterns of low participation in certain beneficial activities or communities, students may be at a disadvantage, and participation could be encouraged more within the institutional culture.

As discussed above, although the K-12 literature largely points to the academic and personal benefits of students' extracurricular participation, studies of higher education show mixed results. Our findings suggest that the mixed messages sent by higher education research may be due to the fact that variation among institutional cultures makes it impossible to generalize across the national undergraduate student population. This means that in order to understand how our own students are impacted by extracurricular participation, and to determine which types of participation to promote or facilitate in the interest of academic benefits for students, looking to national trends is at best a starting point.

\section{Concluding Remarks}

This study examined whether institutional culture might contribute to differences in the types of activities students choose, the amount of time they spend in those activities, and how these activities are associated with academics. Based on our findings, we conclude that institutional culture, rather than students' gender or race/ethnicity, has the greatest influence on what undergraduate engineering, computer science, and math students do outside of class and how often they do it. All institutions have unique characteristics, some of which are shared with other schools of similar size, focus, or geographic region, while others are products of that institution's singular identity, history, and student population. These characteristics appear to be powerful variables in determining the ways in which students participate in various activities, including extracurricular communities. Among the institutions in our study, the smaller institutions tend to have more involved students, regardless of Carnegie classification. In addition, those institutions with faith-based missions or cultures seem to have significant levels of involvement in extracurricular activities or communities that have a positive impact on academics.

Simply asking how much time students should spend participating in extracurricular activities, or even in which activities they should engage, may be the wrong questions. Instead, we suggest 
first examining individual institutional cultures in order to determine our students' realistic availability for extracurricular participation, and which communities and activities are accessible and encouraged on our campuses. Then we may gain clearer insight into how best to help our students achieve the full benefits of extracurricular participation. Ultimately, we argue that educators need to be aware of what students are doing (including outside the classroom), be aware of what helps and what hinders academic engagement, and support those activities that are helpful and which students tend toward at that particular institution.

\section{Bibliography}

1. Pascarella, E.T. \& Terenzini, P.T. (2005). How college affects students: A third decade of research. San Francisco, CA: Jossey-Bass.

2. Inman, P. \& Pascarella, E. (1998). The impact of college residence on the development of critical thinking skills in college freshmen. Journal of College Student Development, 39(6):557-568.

3. Brint, S. \& Cantwell, A.M. (2006). Undergraduate time use and academic outcomes: Results from the University of California undergraduate experience survey 2006. Teachers College Record, 112: 2441-2470.

4. Fischer, M.J. (2007). Settling into campus life: Differences by race/ethnicity in college involvement and outcomes. The Journal of Higher Education, 78(2):125-161.

5. Wilson, D., Plett, M., VanAntwerp, J., \& Bruxvort, C. (2011). Opportunities to serve: Important from middle school to retirement. Paper presented at the WEPAN (Women in Engineering Programs and Advocates Network) Annual Conference, June 2011, Seattle, WA.

6. Atman, C. J., Sheppard, S. D., Fleming, L., Miller, R., Smith, K., Stevens, R., Streveler, R., Loucks-Jaret, T., \& Lund, D. (2008). Moving from pipeline thinking to understanding pathways: Findings from the academic pathways of engineering undergraduates. In Proceedings of the American Society for Engineering Education Annual Conference, June 2008, Pittsburgh, PA.

7. Chachra, D., \& Kilgore, D. (2009). Exploring gender and self-confidence in engineering students: A multimethod approach. In Proceedings of the American Society for Engineering Education Annual Conference, June 2009, Austin, TX.

8. Lee, L. A., Hansen, L. E., \& Wilson, D. (2006). The impact of affective and relational factors on classroom experience and career outlook among first-year engineering undergraduates. In Proceedings of the Frontiers in Education Conference, October 2006, San Diego, CA.

9. Loshbaugh, H. G., Hoeglund, T. J., Streveler, R. A., \& Breaux, K. (2006). Engineering school, life balance, and the student experience. In Proceedings of the American Society for Engineering Education Annual Conference, June 2006, Chicago, IL.

10. Stevens, R., Amos, D. M., Garrison, L., \& Jocuns, A. (2007). Engineering as lifestyle and a meritocracy of difficulty: Two pervasive beliefs among engineering students and their possible effects. In Proceedings of the American Society for Engineering Education Annual Conference, June 2007, Honolulu, HI.

11. Zehner, A. (2011). Co-curricular activities and student learning outcomes. Accessed March 2013 from: http://www.purdue.edu/vpsa/news/2011/11/09/involvement-leads-to-success/Co-Curricular-Activities-StudentLearning-outcomes.pdf

12. Massi, L., Lancey, P., Nair, U., Straney, R., Georgiopoulos, M., \& Young, C. (2012). Engineering and computer science community college transfers and native freshmen students: Relationships among participation 
in extra-curricular and co-curricular activities, connecting to the university campus, and academic success. In Proceedings of the Frontiers in Education Conference, October 2012, Seattle, WA.

13. Choudhary, M. A. (2012). Factors influencing engineering student' performance and their relationship with the student satisfaction with the teaching, learning as well as overall university experiences." In 2012 International Conference on Information Technology Based Higher Education and Training (1-4673-2334-9, 978-1-46732334-5), 1.

14.LaNasa, S.M., Olson, E., \& Alleman, N. (2007). The impact of on-campus student growth on first-year student engagement and success. Research in Higher Education, 48(8):941-966.

15. Iwasaki, Y. (2003). Roles of leisure in coping with stress among university students: A repeated- assessment field study. Anxiety, Stress \& Coping: An International Journal, 16(1): 31-57.

16.Hull IV, R.B., \& Michael, S.E. (1995). Nature-based recreation, mood change, and stress restoration. Leisure Sciences: An Interdisciplinary Journal, 17(1):1-14.

17. Trenberth, L., Dewe, P., \& Walkey, F. (1999). Leisure and its role as a strategy for coping with work stress. International Journal of Stress Management, 6(2):89-103.

18. Kleiber, D. A., Hutchinson, S. L., \& Williams, R. (2002). Leisure as a resource in transcending negative life events: Self-protection, self-restoration, and personal transformation. Leisure Sciences, 24(2):219-235.

19. Carnegie Foundation (2010). The Carnegie classification of institutions of higher education. Accessed October 2012 from: http://classifications.carnegiefoundation.org/

20.Plett, M., Jones, D. C., Crawford, J. K., Floyd-Smith, T., Peter, D., Scott, E. Pl, Wilson, D., Bates, R., \& Veilleux, N. M. (2011). STEM seniors: Strong connections to community are associated with identity and positive affect in the classroom. In Proceedings of the American Society for Engineering Education Conference, Vancouver, B.C., June 2011.

21.Lowry, R. (2012). Concepts and applications of inferential statistics. On-line textbook, Chapter 14. Accessed October 2012 from: http://vassarstats.net/textbook/

22. National Survey of Student Engagement (NSSE) (2012). NSSE 2012 annual results. Accessed October 2012 from: http://nsse.iub.edu/NSSE_2012_Results/pdf/NSSE_2012_AnnualResults.pdf

23. National Survey on Student Engagement (NSSE) (2011). Fostering student engagement campuswide. Accessed October 2012 from: http://nsse.iub.edu/html/annual_results.cfm

24.Pew Forum (2012). Religious landscape survey, maps. Accessed December 2012 from: http://religions.pewforum.org/maps

25.Pew Forum (2012) A Religious Portrait of African Americans. Accessed December 2012 from: http://www.pewforum.org/A-Religious-Portrait-of-African-Americans.aspx

26. National Survey on Student Engagement (NSSE) (2007). NSSE 2007 annual report on student engagement. Accessed December 2012 from: http://nsse.iub.edu/NSSE_2007_Annual_Report/docs/withhold/NSSE_2007_Annual_Report.pdf

27.Pew Forum (2012). Pew-Internet: Social networking. Accessed December 2012 from: http://pewinternet.org/Commentary/2012/March/Pew-Internet-Social-Networking-full-detail.aspx

28. StateUniversity.com (2012). U.S. university directory, Tuskegee University. Accessed December 2012 from: http://www.stateuniversity.com/universities/AL/Tuskegee_University.html 
29. Miksza, P. (2007). Music participation and socioeconomic status as correlates of change: A longitudinal analysis of academic achievement. Bulletin of the Council for Research in Music Education, 172:41-58.

30. Mooney, M. (2010). Religion, college grades, and satisfaction among students at elite colleges and universities. Sociology of Religion, 71(2):197-215.

31. Allendoerfer, C., Wilson, D., Bates, R., Crawford, J., Jones, D., Floyd-Smith, T., Plett, M., Scott, E., \& Veilleux, N. (2012). Strategic pathways for success: The influence of outside community on academic engagement. Journal of Engineering Education, 101(3):512-538.

32. Paul, J.A., Baker, H.M., Cochran, J.D. (2012). Effect of online social networking on student academic performance. Computers in Human Behavior, 28(6):2117-2127. 